\title{
Atomic Event Concepts in Perception, Action, and Belief
}

ABSTRACT: Event concepts are unstructured atomic concepts that apply to event types. A paradigm example of such an event type would be that of diaper changing, and so a putative example of an atomic event concept would be DADDY'S-CHANGING-MY-DIAPER. ${ }^{I}$ I will defend two claims about such concepts. First, the conceptual claim that it is in principle possible to possess a concept such as DADDY'S-CHANGING-MY-DIAPER without possessing the concept DIAPER. Second, the empirical claim that we actually possess such concepts and that they play an important role in our cognitive lives. The argument for the empirical claim has the form of an inference to the best explanation and is aimed at those who are already willing to attribute concepts and beliefs to infants and nonhuman animals. Many animals and prelinguistic infants seem capable of re-identifying event-types in the world, and they seem to store information about things happening at particular times and places. My account offers a plausible model of how such organisms are able to do this without attributing linguistically structured mental states to them. And although language allows adults to form linguistically structured mental representations of the world, there is no good reason to think that such structured representations necessarily replace the unstructured ones. There is also no good reason for a philosopher who is willing to explain the behavior of an organism by appealing to atomic concepts of individuals or kinds to not use a similar form of explanation when explaining the organism's capacity to recognize events.

We can form empirical concepts of individuals, kinds, properties, event-types, and states of affairs, among other things, and I assume that such concepts function like what François Recanati calls 'mental files' or what Ruth Millikan calls 'substance concepts' (Recanati 20I2; Millikan I999, 2000, 20I7). To possess such a concept one must have a reliable capacity to re-identify the object

I would like to thank the following people for comments on earlier versions of this paper: Zübeyde Karadağ Thorpe, Bill Wringe, Stephen Voss, Ilhan Inan, Jack Woods, Jeremy Koons, Ken Westphal, Ville Paukkonen, Timothy Williamson, Sun Demirli, Merve Tapinç, Müge Kuyumcuoğlu, Oğuz Erdin, Sumesh Mullassery Kettil, Ece Şenbaş, Gözde Yıldırım, Peter Milne, Aran Arslan, Kaan Arıkan, Berke Can, Taylan Susam, Istvan Aranyosi, Alper Yavuz, Arzu Gokmen, François Recanati, Erdinç Boyacı, David Papineau, Cemal Akmese, and a number of anonymous referees. Funding was provided by Boğaziçi University BAP project I 568 I.

${ }^{\mathrm{I}}$ Following standard conventions, I will use capitalization to refer to concepts. I use articulated noun-phrases to refer to event concepts, but this is not meant to imply that the concept is articulated for the possessor of the concept. I assume throughout this paper a household in which only Daddy regularly changes diapers. There is an interesting empirical question as to whether babies who have their diapers changed by both parents start off with a generic concept of DIAPER-CHANGING or first develop two specific concepts-and only later develop the generic concept. 
in question, but this capacity of re-identification does not fix the reference of the concept. Such concepts allow us to collect and utilize useful information about things that we re-encounter in our environment. We can distinguish between a perception-action system and a perception-belief system, and I will argue that empirical concepts, including atomic event concepts, can play a role in both systems. The perception-action system involves the application of concepts in the service of (often skilled) action. We can think of the concept as a mental file containing motor-plans that can be activated once the individual recognizes that they are in a certain situation. In this way, recognizing something (whether an object or an event) as a token of a type, plays a role in guiding immediate action. The perception-belief system, in contrast, allows for the formation of beliefs that can play a role in deliberation and planning and in the formation of expectations. I distinguish between two particular types of belief which I call where-beliefs and when-beliefs, and I argue that we can model the formation of such perceptual beliefs in nonlinguistic animals and human infants in terms of the formation of a link between an empirical concept and a position on a cognitive map. According to the account offered, seemingly complex beliefs, such as a baby's belief that Daddy changed her diaper in the kitchen earlier, will not be linguistically structured. If we think that prelinguistic infants possess such concepts and are able to form such beliefs, it is likely that adults do too. The ability to form such beliefs does not require the capacity for public language, and we can model them in nonlinguistic terms; thus, we have no good reason to think of such beliefs as propositional attitudes. Of course, we can use sentences to refer to such beliefs, and thus it is possible to think of such beliefs as somehow relations to propositions. But it is not clear to me what is gained by this as we have a perfectly good way to think about the structure of such beliefs that does not involve any appeal to language.

KEYWORDS: mental files, perception, memory, cognitive maps, belief, animal cognition, Millikan

\section{Introduction}

Timothy Williamson (2000:38) plausibly claims that any plausible account of perception must be able to distinguish between seeing a situation in which Olga is playing chess and seeing that Olga is playing chess. And he argues that one cannot see that Olga is playing chess without possessing the concept CHESS. I take it that Williamson thinks this claim is conceptually or metaphysically necessary. I will reject this argument, claiming that one is able to see that Olga is playing chess if one possesses the concept OLGA'S-PLAYING-CHESS; because such event concepts do not need to be internally structured, it is possible to possess the concept OLGA'S-PLAYING-CHESS without possessing the concept CHESS. The motivation for such a position should appeal to those who are sympathetic to externalist accounts of the content of natural kind concepts; just as we can have atomic concepts of individuals and kinds, we can also have atomic concepts of event-types and situation-types. Just as the concept WATER applies to a particular 
kind of stuff, the concept OLGA'S-PLAYING-CHESS applies to a particular kind of event. Now, even though water is $\mathrm{H}_{2} \mathrm{O}$, and hence, being water entails containing oxygen, possessing the concept WATER does not entail possessing the concept OXYGEN. Similarly, even though Olga's playing chess entails somebody playing chess, possessing the concept OLGA'S-PLAYING-CHESS does not entail possessing the concept CHESS.

In addition to playing a role in perceptual recognition, atomic event concepts are also involved in what I call where-beliefs, such as the belief that there is beer in the fridge, and when-beliefs, such as the belief that Olga played chess yesterday or that she (generally) plays chess after lunch. Such beliefs involve creating a link between a concept and a position on a cognitive map-thus, they do have some structure, just not a linear sentential structure. My where-belief that there is beer in the fridge involves creating a link between the concept BEER and a particular position on my cognitive map of my apartment. The belief that Olga (generally) plays chess after lunch involves creating a link between the concept OLGA'S-PLAYING-CHESS and a position on my cognitive map of a (generic) day. Thus, it is possible in principle that one can believe that Olga plays chess after lunch without possessing the concept CHESS. ${ }^{2}$ Where-beliefs and when-beliefs are beliefs about the occurrence of particular objects, instances of kinds, stuffs, events, and states of affairs at particular times and places. Such beliefs do not require the possession of language. For example, a chimpanzee may believe that there are (now) fruits in a certain part of the forest or that a lion has been in the vicinity recently. And a prelinguistic infant may believe that she ate before playing with her mummy or that daddy is now changing her diaper. When one attributes these beliefs, one uses syntactically structured English sentences, but one does not need to attribute syntactically structured representations to animals and infants in order to attribute such beliefs to them. To possess when-beliefs and where-beliefs, an animal merely needs (a) a concept of the individual, kind, or event type and (b) some sort of inner cognitive map. These maps can be either spatial or temporal, and the concepts involved in such beliefs need not have any internal syntactic structure. This account is designed to be empirically plausible and to apply to nonlinguistic animals and prelinguistic infants, who are capable of both perceptually guided action and remembering the spatial and temporal locations of objects and events.

In adulthood, our capacities for perceptually guided action and belief formation are clearly greatly enhanced by the development of our linguistic capacities; for example, with the development of language our range of concepts is massively increased, and we can form when-beliefs and where-beliefs as the result of testimony. But I assume for evolutionary and developmental reasons that adult perception is not radically different from animal perception, and so we should

\footnotetext{
${ }^{2}$ There are at least two types of when-beliefs. Beliefs about particular past episodes (which are related to episodic memory), such as the belief that Olga played chess yesterday, and beliefs about regularly occurring events, such as the belief that Olga plays chess (every afternoon) after lunch. These beliefs involve different types of temporal maps.
} 
assume that our basic capacity to form when-beliefs and where-beliefs is not dependent upon our linguistic capacities.

On this account, what Williamson refers to as seeing that is a form of recognition, which involves grasping an object, event, or state of affairs conceptually. Like many philosophers, I believe that the most plausible theory of concepts is a version of an externalist direct reference account, according to which the reference of a concept is determined by its function. One way of thinking about such concepts is as mental files. There are three important aspects of concepts understood as mental files. First, they have an extension. Second, they are used to store information. And third, we normally have a reliable but fallible way of recognizing instances of the concept. The extension of a concept is fixed neither by the information contained in the file nor by our means of recognizing instances of the concept. Rather, the extension is fixed by the function of the concept. Thus, for example, one can think of the acquisition of an empirical concept such as CAT as involving the creation of a cat-file, which can then be used to store useful information about cats. The function of the file is to collect and store useful information about cats. Similarly, the function of the Olga's-playing-chess-file, if we possess one, is to collect and store information about events of this type.

It is clear that many nonlinguistic animals are able to recognize and reidentify individual objects and members of certain kinds, and thus it is plausible to assume that they possess concepts of individuals and kinds. There are good reasons to think, however, that many animals, including great apes and prelinguistic infants, also have the capacity to recognize and re-identify event and situation types. For example, most infants seem to learn to re-identify the event of diaper changing. If we are willing to ascribe concepts to such animals in the first kind of case, there is no good reason not to tell a similar story in the second kind of case.

If we think that seeing that involves the exercise of recognitional capacities that may play a role in immediately guiding action and that belief formation has to do with the formation of mental states that play a role in offline deliberation and planning, then it seems likely that there will be frequent cases of perceptual knowledge without belief, for often there is simply not enough time for deliberation and planning. And by the time one does have an opportunity to reflect and deliberate, the situation has changed, and there will be no need to store information. Given that belief formation is likely to have some costs, it is likely that we will not form beliefs concerning everything we recognize. Good examples of such situations are complex learned skilled activities, where we often use quite complex perceptual capacities in a way that is too quick for the deliberative system to come into play. For example, the event-concept CAR-AHEAD-SLOWING-DOWN plays a role in the skilled picking up of a particular affordance, setting in train and guiding the driver's reaction, often without attention. The development of these perceptual capacities may be influenced by our higher cognitive capacities, as acquiring such concepts and learning to apply them accurately often takes a long period of conscious training; such training is often guided by language. But once we have acquired a certain perceptual skill, there will often be no time and no need for conscious deliberation and therefore no need for belief formation. In the absence of any need to form the corresponding belief, I suspect that we often fail to form beliefs about what we 
perceptually recognize. According to the model I am defending, such beliefs play no role in the immediate guidance of action, and in cases where things are changing quickly there seems to be no strong need for forming beliefs that could play a role in future deliberation. Therefore, I suggest it is highly likely that seeing that often does not lead to the formation of the corresponding where-beliefs and when-beliefs. For example, I can see that the car ahead is slowing down and react appropriately without forming the corresponding belief.

\section{Bees and Babies}

In order to motivate my account of the relationship between perception and belief, I will show how it can be used to model the cognition of very simple organisms, bees (for a defense of the claim that bees do literally have beliefs and desires, see Carruthers [2006:69-78]). The function of the following discussion of bees is to show how my way of thinking of the distinction between the perception-action system and the perception-belief system and the role of concepts for each system can be applied to the simple case of bees. ${ }^{3}$ And then I will try and show how this account can be scaled up to involve more complex cases involving event concepts. The main function of this discussion of bees is to show the descriptive and conceptual adequacy of my model of cognition. This descriptive claim is supposed to play a role in supporting an inference to the best explanation argument to support my empirical claim about the role of concepts and beliefs in our cognitive economy. A background assumption here is the methodological principle advocated by Paul Grice that in offering an account of psychological concepts we should aim to 'safeguard the unity of psychological concepts in their application to animals and to human beings' (I99I:I42). For Grice this commitment is central to his program of 'creature construction', which is part of a constructivist program of conceptual clarification and justification. I am sympathetic to his general methodology and agree that the best way of clarifying our own psychological concepts is by offering a series of increasingly complex psychological models of increasingly complex creatures. And so my following discussion of psychological models of organisms of various levels of complexity can also be understood in Gricean terms as designed to play a role in clarifying our own psychological concepts.

Where-beliefs. Bees leave the hive in search of nectar. They may begin by foraging, but when they find flowers, they will start harvesting nectar; having collected the nectar, they will return to the hive. If, among other things, (a) they found a good source of nectar, (b) there are a number of bees waiting around the hive, and (c) there is evidence that the hive is low on nectar, the bee will communicate the

\footnotetext{
${ }^{3}$ The claim that bees have both a perception-action system and a perception-belief system does not entail that bees have two streams of visual processing in the way that primates seem to have. The distinction between these two systems in bees is functional, and I assume these functionally distinct systems are underwritten by distinct brain circuits. In primate visual perception, following Milner and Goodale (2008), I suspect that the distinction between these two systems corresponds to the distinction between the dorsal and ventral streams of visual processing. But my distinction between these two systems does not presuppose the existence of two separate streams of visual processing.
} 
source of the nectar with a dance. This dance is in the form of a figure eight and communicates two pieces of information: the direction and distance from the hive (Gould I986; Gould and Gould I988; and Menzel 20II). There is strong empirical evidence that bees navigate using an internal, allocentric map of their local environments, probably using a polar coordinate system with the hive at the center. Evidence for the existence of such maps is the fact that, as Menzel et al. (2005) have shown, bees are able to take novel shortcuts between points. Cruse and Wehner (20II), however, are skeptical of Menzel's claims and have argued that the capacity to use novel shortcuts between known points does not require an internal cognitive map. For a convincing response, see Cheeseman et al (20I4). There is also evidence that bees have a separate map of the interior of the hive.

We can think of the bee as having three interrelated cognitive systems: a perceptual system, a navigation system, and a where-belief formation system. Bees have an innate capacity to recognize flowers, and when they find a patch of flowers, they start harvesting the nectar. We can think of this capacity as involving the existence of a concept FLOWER. And we can think of this concept as a very simple mental file that contains simple instructions and links to motor plans. In particular, we can think of the FLOWER file as containing something like the following instruction: If flowers are detected and nectar has not already been collected, the bee starts harvesting. Thus, once the bee recognizes a flower, it will change its activity from foraging to harvesting. Now, recognizing a flower does not just lead to a change in activity, but it also leads to the formation of a where-belief. The bee forms the belief that there are flowers at this particular location, and this belief will play a role in future planning and communication when it returns to the hive. The bee is able to form a where-belief by associating a point on its internal map with the concept FLOWER. Let us call this point on the map point $p$. We can say that the perception of flowers causes the bee to form the belief that there are flowers at point $p$. When the bee returns to the hive, the bee can use this belief either to communicate this information to other bees or to return to the spot itself to collect more nectar. Bees also dance to communicate the location of water, resin, and new nest sites (Menzel, 20I I).

Similarly, there is behavior evidence that chimpanzees 'use long-term spatial memory to monitor food sources' and 'aim travel actively towards specific trees to check for the availability of new fruit' (Janmaat et al. 20I3:II). Forest chimpanzees live in dense forests with low visibility and where ripe fruit (which is their main food source) is distributed irregularly both spatially and temporally. They are skilled foragers who are able to return to a particular high-quality feeding tree from various directions and when they do so they take a linear path, suggesting that they are not navigating by using landmarks but instead use an internal Euclidian cognitive map (Ban and Normand 20I9; thus, Ban and Normand conclude that 'Taï chimpanzees keep a map of their territory in mind, including a notion of direction and feeding tree locations' [2019:442]). There is evidence that chimpanzees return to particular individual trees that were rich in fruit in previous years (Janmaat 20I9:457). There is also behavioral evidence that chimpanzees and other primates use the discovery of ripe fruit on one tree as evidence for fruit on other trees of the same species-which suggests that they do 
not just store information about individual foraging places, but also about species. (Janmaat 20I9:454). This indicates that chimpanzees possess concepts of both individual trees and species. And I suggest that the best way to explain the behavioral evidence is in terms of the creation of a link between concepts (of individuals and kinds) and positions on cognitive maps.

It is highly likely that adult human beings are also able to form where-beliefs in a similar way, and such beliefs should not be thought of as linguistically structured. We have various internal maps: for example, I have a rough internal map of my apartment, of my local neighborhood, of London, and so on. And we are able to link various concepts to positions on these maps. Thus, my belief that there is beer in my fridge, which plays an important role in my long-term deliberation and planning, involves marking the concept BEER as instantiated at a certain point on my internal map of my apartment. And assuming that we also have atomic concepts of events, I can also form many beliefs that would seem much more complex when expressed linguistically in a similar way. It seems plausible that one way we have of keeping track of where things are does not involve linguistically encoded information.

Now this simple process can break down for a number of different reasons-and thinking about the way in which a simple system like the one described above could break down allows us to provide a simple taxonomy of various forms of cognitive misrepresentation. Even if one does not think that bees literally have beliefs, the simple taxonomy of forms of misrepresentation that this simple model allows us to build is one that can be applied to human cognition. This simple model suggests that we need to distinguish between at least three possible ways of forming false beliefs, which we can call (I) misperception, (2) mislocation, and (3) misbelief. Misperception involves deploying an inappropriate concept in perception, and such misperception usually causes us to form the corresponding false belief. Thus, for example, I may misperceive a bottle of iced tea as a bottle of beer and form the false belief that there is beer in the fridge. Mislocation, on the other hand, is the formation of false when-beliefs and where-beliefs as a result of mislocating oneself. For example, I may think I am in my own apartment and see beer in the fridge and so form the belief that there is beer in my fridge, but I am actually in an apartment very similar to my own in another city. (We could be in the position of the protagonist in the classic Soviet film, Irony of Fate.) Misbelief is the formation of a false belief in the absence of misperception or mislocation. And there are many such sources of false belief. For example, I may form a false belief as a result of reasoning or on the basis of testimony or because my belief system is damaged. Finally, there may be a breakdown between the perceptual recognition system and the belief formation system, such that the perceptual recognition does not cause the corresponding belief because of a lack of communication between the perceptual system and the belief system (or perhaps because this communication is overridden). We can call such a 'breakdown' a lack of belief formation.

When-beliefs. There is also behavioral evidence that animals are capable of storing temporal information; for example, bees can learn to return to a feeder at a particular time of day when it has been replenished. For chimpanzees the 
'availability of nutritious rainforest food, like young leaves and ripe fruit, can be highly episodic and patchily distributed in time and space' (Janmaat et al. 20I4:I6344). As a result, chimpanzees have to keep track not only of where the best fruit trees are to be found, but also of when the fruit on particular trees is ripe, and there is behavioral evidence that wild chimpanzees are capable of learning about both the spatial and temporal locations of good sources of food. One form of evidence has to do with the fact that chimpanzees seem to leave their camp for breakfast earlier when the fruit they plan to eat is (like figs) 'ephemeral' in the sense that it is more likely to be depleted quickly by other animals. This behavior suggests that their planning is not just sensitive to spatial information, but also to temporal information (Janmaat 2019:460). There is, then, good experimental evidence that chimpanzees have at least short term "what, where and when' memory' (Janmaat, Ban, and Boesch 2013:2). Although the behavioral evidence for storage of temporal information is less extensive than that for spatial evidence, it is clear that many nonhuman animals do somehow encode temporal information.

There is also strong behavioral evidence that prelinguistic infants are capable of forming when-beliefs and not just about the temporal location of objects, but also about the temporal location of events as they start learning daily routines at some point during their first year. Thus, Nina Vaid Raoji argues, 'when the same thing is done at approximately the same time interval, baby quickly learns the sequence and will anticipate the next step' ${ }^{4}$

The best way of modeling such capacities in infants is in terms of the creation of a link between an event concept and a position on a (one-dimensional) temporal map. For example, forming the belief that a certain event happens at a certain time involves marking an event concept as instantiated at a particular point on a temporal cognitive map. One form of such a temporal map will be a simple timeline. Such timelines play an important role in ordering memories. But in addition to simple timelines, we also seem to possess cyclical timelines that allow us to recognize and create routines by keeping track of the order and the timing of regularly repeated event types. Thus, for example, it seems that in their first year, human babies develop something like a map of a day and then work out which events are regularly repeated in which order, learning when to expect breakfast, lunch, dinner, and bedtime and other daily routines. Later in development, the child may learn additional cyclical timelines, such as the week and the year, in order to learn weekly and yearly routines. We also seem to possess a simple (noncyclical) linear map of the past, which can play a role in ordering nonlinguistically formulated episodic memories. Forming a particular when-belief, then, can be thought of as creating a link between an (event) concept and a position on one of these temporal

\footnotetext{
${ }^{4}$ Quoted from 'What You Need To Know About Setting A Baby Schedule', https://www.thebump.com/a/babyschedules. In the same argument, Cheryl Wu argues that 'At 3 months, you'll notice that baby has some sort of pattern throughout the day. . . . Usually around 6 months, they'll get into a rhythm for nighttime sleep, sleeping about 12 hours at night and waking up two or three times throughout the night. A daytime schedule emerges for most babies around 9 months of age.' I believe that the judgment of healthcare professionals and primary caregivers is a good source of evidence about such matters. For a good discussion of the epistemic value of the judgments of primary caregivers, see Reddy (2010).
} 
maps. Importantly, these capacities can be explained without attributing linguistically structured representations to the infant.

The position I have just sketched posits the existence of both spatial and temporal cognitive maps and the existence of (atomic) concepts, not only of individuals and kinds, but also of situations and events. In the following section I present empirical evidence for the existence of internal cognitive spatial and temporal maps. It is significant that their neural implementation seems to be located in the hippocampus. There is also evidence that 'concept cells' are also located in the hippocampus. This suggests as an empirical hypothesis that the hippocampus plays a critical role in the formation of when-beliefs and where-beliefs. In the section after that, I will defend the existence of atomic events and situation concepts, arguing that anyone who is happy to posit atomic concepts of individuals and kinds should be comfortable with atomic concepts of events and situations.

\section{Spatial and Temporal Cognitive Maps}

The existence of spatial cognitive maps in mammals is well established. Following John O'Keefe's seminal work on 'place cells' in rats, it is now widely accepted that mammals have internal cognitive maps, with strong evidence for the existence of such maps provided both by brain studies and behavioral studies. O'Keefe discovered that particular nerve cells in the hippocampus, which he called 'place cells', were activated when a rat was in a certain location. These cells seem to form a two-dimensional (horizontal) map of the environment (see O'Keefe and Dostrovsky I97I; O'Keefe I976). O'Keefe argued that the hippocampus is able to form multiple maps of its various environments and that these play a central role in spatial memory, planning, and deliberation. Later work by May-Britt Moser and Edvard Moser, with whom O'Keefe was jointly awarded a Nobel Prize in 20I4, demonstrated the existence of 'grid cells' in the entorhinal cortex, which are closely linked to the place cells (see Fyhn et al. 2004); Sargolini et al. 2006). These grid cells seem to play a role in applying a metric to the cognitive map encoding directionally tagged distances, functioning somewhat like an odometer (see Jeffery 20II:26). As O'Keefe (I993:36-37) explains, 'cognitive maps... consist of a set of places and a mechanism for linking these place representations together in terms of the distance and direction between them.' A similar neural system seems to be found in all mammals, including human beings. In patients with Alzheimer's disease, the hippocampus and entorhinal cortex are often damaged in the early stages of the disease, and this damage seems to be the neurological cause of problems with navigation and spatial memory. The neurological and behavioral evidence for temporal cognitive maps is weaker than for spatial maps-but perhaps this is merely a function of the greater difficulty in collecting data on temporal as opposed to spatial cognition and the fact that less work has been done on this topic. Already in the late I990s O'Keefe argued that while there was no evidence that rats have temporal maps, there was already strong evidence that human beings do have a spatial-temporal system and that this plays a role in remembering narratives (O'Keefe I993:44). And more recent work seems to have demonstrated the existence of temporal cognitive maps and the existence of cells 
functioning as 'time cells' in addition to place cells in nonhuman mammals as well as in human beings. These time cells are neurons in the hippocampus that 'fire at specific moments in temporally structured experiences' and, in effect, keep track of the temporal order and duration of events (Salz et al., 20I6:7476). Buzsáki and Llinás (2017) have shown that for rats, 'during wheel or treadmill running in a memory task, the ordinal sequence of neurons faithfully track elapsed duration (termed "time cells")' (483). Damage to the hippocampus in both human beings and rats interferes with the capacity to learn and remember the sequential order of events. ${ }^{5}$ Similar results have been shown by Schiller et al. (2015), who argue that 'numerous studies have revealed that the hippocampus plays a critical role in remembering the order of events in specific experiences' (I3905). Summing up this recent research, Eichenbaum argues that time cells may:

play a role in episodic memory by tagging when events occur in time, just as place cells map where events occur in space so that the hypothesis is that time cells do for memory the same things that place cells do. Considered together, time cells and place cells organize events in different relational dimensions to provide cognitive maps in time and space respectively. (Lisman et al. 20I7:I439)

We have strong empirical evidence, then, that human beings and other mammals possess internal spatial and temporal cognitive maps and neuroscientists are beginning to understand how such maps are implemented neuronally in the hippocampus. There is also some evidence for the existence of 'concept cells' in the hippocampus. These are cells that 'respond in a remarkably selective and abstract manner to particular persons or objects' (Quiroga 20I 2:587). I have suggested that we can think of where-beliefs and when-beliefs as establishing connections between concepts and positions on such maps. Where-beliefs involve creating a link between a concept and a position on a spatial map (perhaps encoded by a system of place cells), and when-beliefs involve creating a link between a concept and a position on a temporal map (perhaps encoded by a system of time cells). Given that there is strong evidence for the localization of cognitive maps to the hippocampus and some evidence for the existence of 'concept cells' in the hippocampus, it does not seem implausible as an empirical hypothesis that the hippocampus plays a critical role in the formation of when-beliefs and where-beliefs, which might involve the creation of neuronal connections between 'concept cells' and cognitive maps. Given that the hippocampus is not thought to have a central role in linguistic processing, such a localization would support the idea that where-beliefs and when-beliefs should

\footnotetext{
5 'When patients with hippocampal damage were examined after a tour around a campus, they could recall spatial and temporal aspects and details about particular events. However, whereas control participants could well remember the sequential order of the tour events even a month later, the patients' recalled order of events was unrelated to reality. . . . Hippocampal damage in rats also induces a deficit in learning sequential order of odor stimuli’ (Buzsáki and Llinás 2017:484).
} 
not be modeled in linguistic terms. Although research in this area is at an early stage, the model I am defending is, at the least, consistent with recent empirical work.

\section{Event Concepts as Substance Concepts}

In addition to being committed to the existence of internal spatial and temporal cognitive maps, my account presupposes that we have concepts not only of individuals, kinds and stuffs, but that we also have concepts of event types and situation types. Such atomic event and situation concepts can be thought of as what Ruth Millikan (I999) calls 'substances concepts'. For Millikan, the ontological category 'substances', as she uses the term, is roughly 'that extensive category consisting of items about which it is possible to learn from one encounter something about what to expect on other encounters' (528). And the concept of a substance 'is the capacity to represent the substance in thought for the purpose of information gathering and storage, inference, and ultimately the guidance of action' (530-3 I; see also Millikan [2000:I3]; I prefer Millikan's earlier expression 'substance concept' rather than her more recent [20I7] term 'unicept').

The function of substance concepts is not to classify things or to describe them, but to identify and re-identify them in the service of informed action. Millikan herself focuses on three types of substance concepts: concepts of individuals (Mama), kinds (mouse), and stuffs (milk). She suggests, however, without elaborating on it, that event-types can also be substances in this sense, for there are many types of event about which one can learn on a single encounter how to behave on future encounters with the same event-type. In particular, it seems clear that infants show a capacity for re-identifying event types that are parts of social routines, and the capacity to re-identify such events plays an important role in early learning. For example, a baby is able to recognize when her father is about to change her diaper and learns how to move her legs in a cooperative way. Diaper changing is an event type that recurs frequently and creates a regular structure in a baby's life. But in order to learn how to cooperate, the baby must have a capacity to re-identify the event type. That is, the baby must possess the relevant substance concept, perhaps in this case, the concept DADDY'S-CHANGING-MY-DIAPER. One could tell a similar story about the capacity to re-identify the event type of 'being picked up'. Reddy, Markova, and Wallot (2013) have shown that even at two months, babies are able to anticipate and therefore recognize when they are about to be picked up. This capacity to re-identify event types plays an enormous role in our cognitive lives and development, and hence event concepts must also play a central role. From the evidence available, it seems that chimpanzees are capable of learning event concepts that play a role in guiding action. And the evidence from foraging behavior suggests that they are capable of forming when-beliefs and where-beliefs about individuals and kinds. It is not clear, however, whether they are able to form when-beliefs and where-beliefs about events.

There is evidence that some nonhuman primates possess such a capacity for re-identifying social event types, and thus they would possess substance concepts of these event types in Millikan's sense. For example, chimpanzees are able to 
recognize a hand-raise signal as an invitation to play. This is a clear case of learning to recognize and re-identify a particular event type. Tomasello (2008) offers a plausible three-stage account of how chimpanzees learn to pick up on a hand-raise as an invitation to play in the following terms:

(i) initially one youngster approaches another with rough-and-tumble play in mind, raises his arm in preparation to play-hit the other, and then actually hits, jumps on, and begins playing; (ii) over repeated instances, the recipient learns to anticipate this sequence on the basis of the initial arm-raise alone, and so begins to play upon perceiving this initial step; and (iii) the communicator eventually learns to anticipate this anticipation, and so raises his arm, monitors the recipient, and waits for her to react-expecting this arm-raise to initiate the play. (23)

I suggest that at stage two, what the chimp perceives when he sees the initial step is that the other chimp wants to play. Nim indicates that he wants to play by raising his arm and Chim has learnt to recognize this arm-raising as an invitation to play. In such a case, it is clear that Chim does not just see a scene in which Nim is inviting him to play, but he sees that Nim is inviting him to play, and I take it that the best explanation for this is that Chim possesses the relevant event-concept. The event type is that of an invitation to play, and Chim is has learnt to recognize tokens of this type of event and respond appropriately. I take it that this offers support for the empirical claim that some nonhuman animals possess event concepts.

It is likely that something similar occurs between young infants and their primary carers in the establishment of routines and in terms of the way skilled athletes learn to 'read' their teammates. And there are certain moves that daddy makes when he is about to start changing the baby's diaper; indeed, it is often the case that he has, perhaps not consciously, learnt to make these moves in order to indicate that he wants to change her diaper. And the baby has learnt to pick up on these indications and so is able to see that Daddy is about to change her diaper. There is no good reason to think that we lose this capacity to form atomic event concepts in adulthood.

\section{Seeing Olga's Playing Chess}

Williamson (2000: 38 ) argues that

There is a distinction between seeing that A and seeing a situation in which A. One difference is that only the former requires the perceiver to grasp the proposition that A. A normal observer in normal conditions who has no concept of chess can see a situation in which Olga is playing chess, by looking in the right direction, but cannot see that Olga is playing chess, because he does not know what he sees to be a situation in which Olga is playing chess. 
Williamson is right that any adequate account of perceptual knowledge has to be able to give an account of the distinction between seeing a situation in which Olga is playing chess and seeing that Olga is playing chess. I argue, contra Williamson, that one can see that Olga is playing chess without possessing the concept CHESS. An infant can possess the concept MUMMY'S-PLAYING-CHESS without possessing the concept CHESS. For such an infant, there will be a clear difference between seeing a situation in which his mother (Olga) is playing chess and seeing that his mother is playing chess. In addition, the infant will be able to form (de re) where-beliefs and when-beliefs about Olga's playing chess by making links between the atomic concept and positions on spatial and/or temporal cognitive maps. For example, he may form the belief that Olga is playing chess in the kitchen by forming a link between the concept and a position on his cognitive map of his house, and he may form the belief that Olga plays chess after lunch by forming a link between the concept and a position on her cognitive map of a day. Thus, the prelinguistic infant may be able to form the belief that his mother played chess after lunch in the kitchen, without possessing the concept chess. And so the distinction between 'seeing a scene in which' and 'seeing that' need not be cashed out in terms that involve 'grasping a proposition', as Williamson suggests. And being able to see that does not require any linguistic capacities or linguistically structured mental states. Instead, what is involved in the type of perceptual knowledge expressed by the English sentence 'Tim sees that Olga is playing chess' is that Tim accurately grasps a situation in which Olga is playing chess by deploying the concept OLGA'S-PLAYING-CHESS. Although we refer to such concepts using complex internally structured phrases, such concepts may be atomic. Indeed, it is likely that in development our earliest concepts of complex event types are atomic, and only later in development do these concepts become articulated. The way in which atomic event concepts become articulated is analogous to the way in which infants, in their linguistic development, slowly come to recognize the internal structure of what start out as holophrases. Empirical research shows that in terms of the development of their linguistic capacities, infants begin by expressing 'complex' thoughts with holophrases, that is, 'one-word utterances with which the toddler expresses an entire sentence' (Rowe and Levine 20I5:236). This is the orthodox position of those who study language acquisition. It is common for infants to learn expressions such as 'ice cream' or 'I love you' as single lexical items before they learn to articulate their internal structure. It is only later in development that they begin to understand the internal structure of such expressions. A similar story should be told about the development of our event concepts, which start as atomic event concepts and are articulated only later in development.

Take, for example, an infant-let us call him Tim. His mother, Olga, plays chess most afternoons with various friends, and Tim has learnt to identify when this particular activity is going on and has stored quite a bit of practical information about what to expect in such situations. In such a case, we can say that Tim has acquired the concept MUMMY'S-PLAYING-CHESS. Although we are able to refer to this concept as MUMMY'S-PLAYING-CHESS, for Tim this is an atomic concept, a concept without internal structure. It is the mental equivalent of a 
singular term-the mental equivalent of the name of an event type; Tim is reliably, albeit fallibly, able to recognize situations in which his mother, Olga, is playing chess and is able to use this capacity to collect and retrieve information about events of this type. Tim may have no understanding that chess is a game that involves turn-taking and winning or losing. But, like us, he is able to identify situations in which Olga is playing chess, but what he takes to be entailed by such a situation is quite different from an adult's understanding of the situation. Tim may understand that he should not knock the pieces over and that his mother will not pay much attention to him.

Over time, Toddler Tim becomes Teenage Tim. Tim learns that chess is a game and that it has winners and losers. He learns how to play chess himself and comes to be able to recognize when his mother is winning or losing and when his mother has just been checkmated. As this learning occurs, Tim's concept of MUMMY'S-PLAYING-CHESS becomes articulated. He will come to recognize, for example, that mummy's playing chess entails somebody's playing chess and mummy's doing something, but there is no good reason to assume that these facts imply that his concept has changed. ${ }^{6}$ Anyone convinced of externalist accounts of concept identity for names should be sympathetic to such an account for event concepts as well. As Putnam argues, 'speakers who lived before Dalton introduced the modern notion of a chemical compound referred to the same liquid when they used the term "water". The word does not change its meaning every time we discover a better account of the nature of water. The meaning and reference of "water" aren't what has changed; it is our knowledge about water that has changed. The meaning of "water" isn't fixed by a definition, either in terms of the observable properties of the substance or in terms of the properties mentioned in our latest scientific theory; it is fixed by the nature of our paradigms of water. To be water is to be the same liquid as this, where this can be (almost) any of the paradigm examples of water' (2016:207-208). I maintain that if both Toddler Tim and Teenage Tim possess a concept of MUMMY'S-PLAYING-CHESS, then we should take the same approach and say that the concept remains the samedespite the fact that over time, Tim's knowledge about what is involved in his mother's playing chess and the inferences he is willing to draw about situations where he recognizes that this concept is applicable may change.

Now, one may question the assumption that Toddler Tim and Teenage Tim both possess the concept MUMMY'S-PLAYING-CHESS. We can lose concepts as well as acquire them. Many of our infant concepts will play no role in our adult life; so it is likely that many infant concepts are lost in development. For this reason, there is a question as to whether Teenage Tim still possesses the atomic concept

\footnotetext{
${ }^{6}$ One might think here that although the earlier and later concept may have the same referent, it is unarticulated for the toddler and articulated for the teenager and in that sense is a different concept. But this depends on how one thinks of articulation. My preference is to think of conceptual articulation in terms of establishing inferential relations between concepts rather than concepts acquiring some sort of internal articulation. Thus, what remains the same through the process of conceptual articulation is not merely the reference. I am thinking of concepts as mental files. On my preferred picture what happens in the process of articulation is that the original file remains the same but a new file is created and an inferential link is created between the original file and the new file. One articulates the concept MUMMY'S-PLAYING-CHESS by creating an inferential link between the concept MUMMY'S-PLAYING-CHESS and the concept PLAYING-CHESS.
} 
MUMMY'S-PLAYING-CHESS. It is possible that once Tim has the concepts MUMMY, PLAYING, and CHESS, he no longer needs the concept MUMMY'S-PLAYING-CHESS. In this case the adult attitude involves forming something like a linguistically structured attitude that involves a number of distinct concepts. One possible story about his development, then, is that Tim loses the atomic concept in the course of development. Whether it happens will be an empirical matter, and whether or not the concept is lost probably depends on the importance in his adult life of his mother's playing chess.

\section{Atomic Event Concepts, Holophrases, and Skilled Action}

One might think that while infants need atomic event concepts because syntactically structured thoughts require the mastery of public language, adults do not need such concepts because we can think (and perhaps see that something is the case) using syntactically structured representations. And so, the thought goes, adults lose any atomic concepts of events that they are able to think of in compositional terms. Here, once again, one can draw an analogy with linguistic representations. One may think that, given the compositionality of language, our linguistic capacities require only that we represent simple lexical items and syntactic rules for their combination. However, there is overwhelming evidence that many seemingly syntactically complex expressions are stored as individual lexical items. Similarly, someone who possesses the concepts PET and FISH could also possess the distinct concept PET-FISH. And it is even possible for someone to acquire the concept PET-FISH before acquiring the other two; perhaps they were raised in a pet-fish shop.

The two most obvious examples of apparently complex expressions that are stored as individual lexical items are idioms and frequently used expressions. ('Like idioms, high frequency phrases also provide evidence for lexical storage of multi-word items as single units, but units which are nonetheless analyzable into their morphosemantic components' [Bybee I998: 425].) Idioms are syntactically complex, with the speaker often understanding much of the syntactic structure, but they seem to be stored in memory as single lexical units. Thus, Bybee (I998) argues that 'it is not controversial to claim that idioms are instances of multi-word sequences that are stored in memory. . . Just because idioms are remembered as wholes does not mean that their component parts and the semantic contribution they make are not recognized. . . Even though a phrase such as pull strings, as in John was able to pull strings to get the job, has a meaning that is different from the literal combination of its parts, speakers recognize the two words in the phrase as the same as those occurring in other combinations, and even recognize the semantic contribution of these words' $(424-25)$.

We find a similar phenomenon with frequently used expressions such as 'I dunno'. Such expressions may begin life as holophrases, but by adulthood, we are well aware of their internal syntactic structure. There is, however, good evidence from psycholinguistics that such expressions are indeed stored as single lexical items. As Tomasello (2003) explains, 'for most speakers of English, I dunno is a fixed expression with a single coherent meaning equivalent to a shrug of the shoulders. 
Its unitary status can be seen by the fact that the pronunciation involves many reduced elements, and indeed on some occasions the word 'don't' can hardly be heard at all. But speakers may also break down this expression into its constituent parts if the need arises. The phonological reductions involved in such cases result from general principles of automaticity in which repetition of a skill leads to smoother and less redundant movements in its execution. . It is also possible that parts of a construction may be automatized, and so unitized, while others are left variable, as in mixed constructions such as Where's-the X?, I-wanna X, Lemme $\mathrm{X}$, Gimme X, I'm-gonna X. The main point from an acquisition point of view is that when a higher abstraction is made the lower-level, more concrete constructions and expressions do not necessarily go away but may remain available for use-especially if they are used frequently" (I06).

A similar story can be told about concepts. There are reasons why an organism may acquire and retain atomic event concepts even though the organism may have developed the capacity to represent the events picked out by such atomic concepts through combining simple concepts according to lexical rules. One plausible reason for retaining both the simple representations and the seemingly more complex representations may be speed. Applying and combining concepts takes time, and time may be of the essence. For this reason atomic event concepts play an important role in skilled activity, and their acquisition plays an important role in skill acquisition. Such concepts can be very specific. Take the case of two professional soccer players: Zübeyde and Gözde. Zübeyde has developed a capacity to recognize situations in which Gözde is about to cross the ball to her and has learnt how to act appropriately. This may involve a very specific recognitional capacity that involves picking up on signals specific to Gözde. Now, if this is the case, and if Zübeyde has learnt to re-identify and respond appropriately to instances of the event type 'Gözde is about to cross the ball', then in Millikan's sense, she possesses the substance concept GÖZDE'S-CROSSING-THE-BALL. Zübeyde is thus likely to possess the concepts GÖZDE and CROSSING-THE-BALL, but there may be situations where it is possible for Zübeyde to recognize that Gözde is crossing the ball (applying the concept GÖZDE'S-CROSSING-THE-BALL) without, at that moment, recognizing Gözde (that is, without applying the concept GÖZDE).

We might think that recognizing that Gözde is about to cross the ball must involve recognizing Gözde and so must involve the application of the concept GÖZDE as part of the act of recognition. But this is not necessarily the case, for all that is required is for Zübeyde to track Gözde and that this tracking has primed the (atomic) concept GÖZDE'S-CROSSING-THE-BALL. She is anticipating a cross and knows what to do if it comes. Now, this tracking may have begun with Zübeyde recognizing Gözde, and so with her applying the concept GÖZDE. But during the game, she is tracking many individuals simultaneously, and empirical research, initially by Pylyshyn and his colleagues (2007) on what they call 'Multiple Object Tracking' (MOT), suggests that such simultaneous tracking does not involve the categorization of the objects once the tracking has begun. Thus, for example, the tracking of an object is not disrupted by the object changing color, size, shape, or kind during its motion (Pylyshyn 2007: 33-58 and Carey 2009: 67-II6). It is possible that while Zübeyde is tracking Gözde and 
anticipating that she might be about to cross and therefore preparing herself to pounce, she need not categorize her as Gözde-even though she is primed to apply the concept GÖZDE'S-CROSSING-THE-BALL to the individual she is tracking. In such a case, Zübeyde may see that Gözde is crossing the ball but not necessarily recognize Gözde at the moment she recognizes that Gözde is crossing the ball. This may seem a strange thing to say, but I think it captures something about the nature of real time immersed skilled activity. What is important for the activity is recognizing the event type (which may be an event type specific to a particular individual, such as the event type of Gözde crossing the ball) and responding appropriately. And there is no good reason to think that this necessarily involves recognizing the individual involved in the event, even if the event type is one specific to the individual. In such a situation it is possible for Zübeyde to see that Gözde is crossing the ball, without, at the time, recognizing Gözde.

LUCAS THORPE

BOGAZICI UNIVERSITESI

lthorpe@gmail.com

\section{References}

Ban, S., and E. Normand. (20I9) 'Spatial Cognitive Abilities in Foraging Chimpanzees'. In C. Boesch and R. M. Wittig (eds.), The Chimpanzees of the Taï Forest: 40 Years of Research (New York: Cambridge University Press), 440-50.

Buzsáki, György, and Rodolfo Llinás. (20I7) 'Space and Time in the Brain'. Science, 358, 482-85. Bybee, Joan. (1998) 'The Emergent Lexicon'. In CLS 34: The Panels. Chicago Linguistic Society, $42 \mathrm{I}-35$.

Carey, Susan. (2009) The Origin of Concepts. Oxford: Oxford University Press.

Carruthers, Peter. (2006) The Architecture of the Mind. Oxford: Oxford University Press.

Cheeseman, J. F., C. D. Millar, U. Greggers, K. Lehmann, M. D. Pawley, C. R. Gallistel, G. R. Warman, and R. Menzel. (20I4) 'Way-finding in Displaced Clock Shifted Bees Proves Bees use a Cognitive Map'. Proceedings of the National Academy of Sciences USA, I I I, 8949-54.

Cruse, H., and R. Wehner. (20I I) 'No Need for a Cognitive Map: Decentralized Memory for Insect Navigation'. PLoS Computational Biology, 7, eroozoog.

Fyhn, M., S. Molden, M. P. Witter, E. I. Moser, and M. B. Moser. (2004) 'Spatial Representation in the Entorhinal Cortex'. Science, 305, I $258-64$.

Gould, J. (I986) 'The Locale Map of Bees: Do Insects have Cognitive Maps?' Science, 232, 86I-63.

Gould, J., and C. Gould. (I 988) The Honey Bee. New York: W. H. Freeman and Company.

Grice, Paul. (1991) 'Method in Psychological Psychology'. In Grice, The Conception of Value (Oxford: Oxford University Press), I 2 I-62.

Janmaat, K. R. L. (2019) 'Temporal Cognition in Taï Chimpanzees'. In C. Boesch and R. M. Wittig (eds.), The Chimpanzees of the Taï Forest: 40 Years of Research (Cambridge: Cambridge University Press), 45 I-66.

Janmaat, K. R. L., S. D. Ban, and C. Boesch. (2013) 'Chimpanzees Use Long-term Spatial Memory to Monitor Large Fruit trees and Remember Feeding Experiences across Seasons'. Animal Behaviour, 86, II 83-I 205 .

Janmaat, K. R. L., L. Polansky, S. D. Banand C. Boesch. (20I4) 'Wild Chimpanzees Plan their Breakfast Time, Type, and Location'. Proceedings of the National Academy of Sciences, I I I, I6343-48 
Lisman, J., G. Buzsáki, H. Eichenbaum, L. Nadel, C. Rangananth, and A. D. Redish. (2017) 'Viewpoints: How the Hippocampus Contributes to Memory, Navigation and Cognition'. Nature Neuroscience, 20, I434-47.

Menzel, Randolf. (20II) 'Navigation and Communication in Honeybees'. In Randolf Menzel and Julia Fischer (eds.), Animal Thinking: Contemporary Issues in Comparative Cognition (Cambridge, MA: MIT Press), 9-22.

Menzel, R., U. Greggers, A. Smith, S. Berger, R. Brandt, S. Brunke, G. Bundrock, S. Hülse, T. Plümpe, F. Schaupp, E. Schüttler, S. Stach, J. Stindt, N. Stollhoff, and S. Watzl. (2005) 'Honey Bees Navigate According to a Map-like Spatial Memory'. Proceedings of the National Academy of Sciences USA, 102, 3040-45.

Millikan, Ruth Garrett. (I999) 'A Common Structure for Concepts of Individuals, Stuffs, and Real Kinds: More Mama, More Milk, and More Mouse'. In Eric Margolis and Stephen Laurence (eds.), Concepts: Core Readings (Cambridge, MA: MIT Press), 525-47.

Millikan, Ruth Garrett. (2000) On Clear and Confused Ideas: An Essay on Substance Concepts. Cambridge: Cambridge University Press.

Millikan, Ruth Garrett. (2017) Beyond Concepts: Unicepts, Language and Natural Information. Oxford: Oxford University Press.

Milner, A. D., and M. A. Goodale. (2008) 'Two Visual Systems Re-viewed'. Neuropsychologia, 46, $774-85$.

O'Keefe, J. (1976) 'Place Units in the Hippocampus of the Freely Moving Rat'. Experiential Neurology, 5I, 78-I09.

O'Keefe, John. (1993) 'Cognitive Maps, Time and Causality'. Proceedings of the British Academy, $83,35-45$.

O'Keefe, J., and J. Dostrovsky. (I97I) 'The Hippocampus as a Spatial Map: Preliminary Evidence from Unit Activity in the Freely Moving Rat'. Brain Research, 34, I7 I-75.

Putnam, Hilary. (2016) 'The Development of Externalist Semantics'. In Mario de Caro (ed.), Naturalism, Realism and Normativity (Cambridge, MA: Harvard University Press), I99-2 I 2.

Pylyshyn, Zenon W. (2007) Things and Places: How the Mind Connects with the World. Cambridge, MA: MIT Press.

Quiroga, R. (20I2) 'Concept Cells: The Building Blocks of Declarative Memory Functions'. Nature Reviews Neuroscience, I3, 587-97.

Recanati, François. (20I2) Mental Files. Oxford: Oxford University Press.

Reddy, Vasudevi. (2010) How Infants Know Minds. Cambridge, MA: Harvard University Press.

Reddy, V., G. Markova, and S. Wallot. (2013) 'Anticipatory Adjustments to Being Picked Up in Infancy'. PLOS ONE, 8, e65289.

Rowe, Bruce M., and Diane P. Levine. (201 5 ) A Concise Introduction to Linguistics. 4 th ed. London: Routledge.

Salz, Daniel M., Zoran Tiganj, Srijesa Khasnabish, Annalyse Kohley, Daniel Sheehan, Marc W. Howard, and Howard Eichenbaum. (20I6) 'Time Cells in Hippocampal Area CA3'. The Journal of Neuroscience, 36, 7476-84.

Sargolini, F., M. Fyhn, T. Hafting, B. L. McNaughton, M. P. Witter, M. B. Moser, and E. I. Moser. (2006) 'Conjunctive Representation of Position, Direction, and Velocity in the Entorhinal Cortex'. Science, 3 I 2, 758-62.

Schiller, D., H. Eichenbaum, E. A. Buffalo, L. Davachi, D. J. Foster, S. Leutgeb, and C. Ranganath. (2015) 'Memory and Space: Towards an Understanding of the Cognitive Map'. The Journal of Neuroscience, 35, I3904-I I.

Tomasello, Michael. (2003) Constructing a Language: A Usage-Based Theory of Language Acquisition. Harvard University Press.

Tomasello, Michael. (2008) Origins of Human Communication. Cambridge, MA: MIT Press. Williamson, Timothy. (2000) Knowledge and its Limits. Oxford: Oxford University Press. 